\title{
GOLD IN GALLIUM ARSENIDE DIE-ATTACH TECHNOLOGY
}

\author{
Giles Humpston and David M. Jacobson \\ GEC Hirst Research Centre, Wembley, Middlesex, U.K.
}

Gold plays an important role in leading-edge semiconductor technologies based on gallium arsenide. This metal is used extensively in contact metallizations and in solders for bonding gallium arsenide devices into packages. The quality of soldered joints made to this semiconductor depends critically on the choice of the metallization/solder combination and bonding temperature. A set of design guidelines for achieving sound joints has been derived from a metảlurgical study, which encompassed a representative selection of metallizations and solders employed in industry.

\section{Introduction}

Recent years have witnessed the development of a new semiconductor device technology that is based on the III-V compounds, principally gallium-arsenide (GaAs). Microelectronic devices made of GaAs can operate much faster and with lower dissipation of energy than those made with existing silicon-based technology. This is because the charge carriers in GaAs have higher mobilities than those in silicon, by almost an order of

Figures 1a-1f illustrate stages in the fabrication of a microwave communications system such as the one shown mounted on a tower in Fig. 1a (right).

Fig. 1b A GaAs wafer, $50 \mathrm{~mm}$ in diameter, containing approximately 200 microwave frequency circuits. $A$ layer of gold, typ-

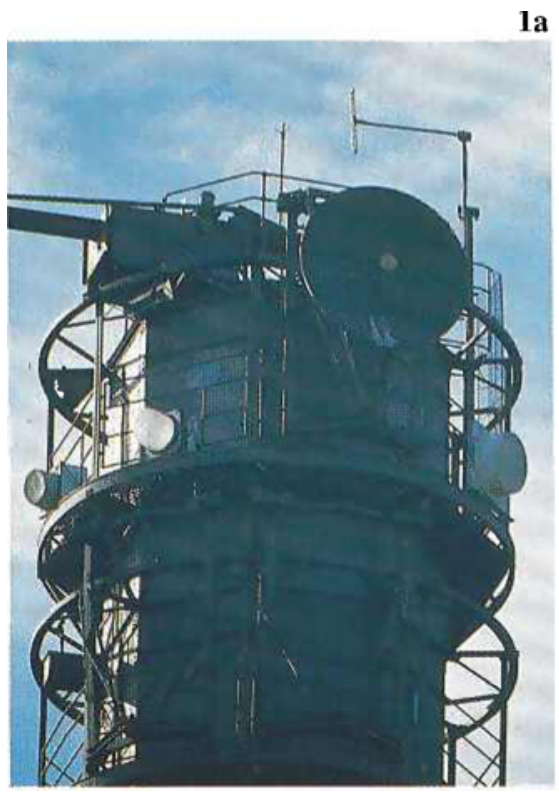

magnitude at low voltages. As a result, GaAs devices can operate at correspondingly higher frequencies. Furthermore, the wider electronic band gap of GaAs means that the noise levels in devices of this material are significantly lower than in silicon devices, thereby permitting the former to operate reliably at significantly higher temperatures and with smaller electrical signals than their silicon equivalents.

At the present time, the main microelectronic application of GaAs is in small-signal analogue devices, like

Ib

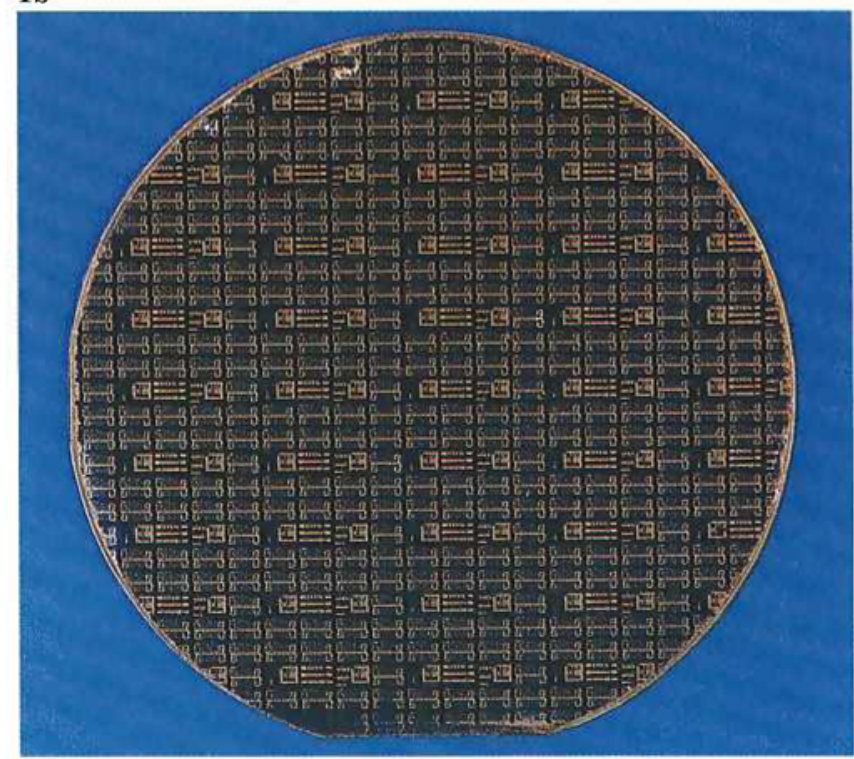


microwave amplifiers, which are entering consumer markets in products such as direct broadcast satellite receivers. This area of application exploits the high frequency capability $(\mathrm{GHz})$ and low noise characteristics of the material. The various stages of fabrication from the processed GaAs wafer containing a batch of circuits through to a complete microwave communications system, are illustrated in the series of photographs (Figures 1a-1f).

The advantages of GaAs over silicon are less decisive for digital microelectronic circuitry. This is because in digital applications the voltage levels are relatively high, so the potential speed factor of GaAs is only two or three times larger than for silicon. In practice, this advantage is further eroded due to the lower drive capability of GaAs, which means that additional circuitry is required

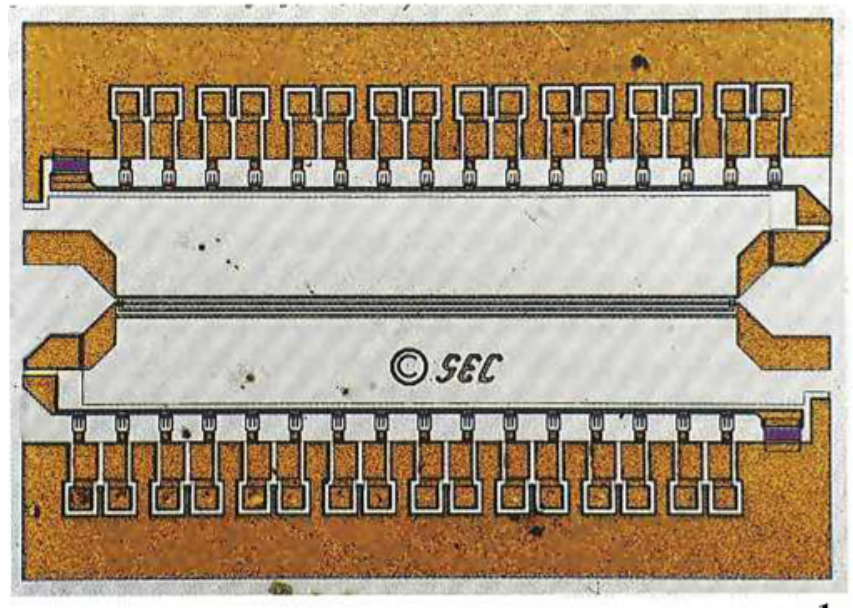

1c



to perform a given function. Consequently, this application area has grown more slowly.

\section{Solder Die-Attach of GaAs Devices}

A microwave (high frequency) device chip in GaAs can be up to several square centimetres in area. Such a 'die' is usually soldered into a ceramic package which is then hermetically sealed to protect the die from atmospheric degradation and mechanical damage. Solders tend to be used for the die-attach operation in preference to organic adhesives because of their superior electrical and thermal conductance, and mechanical and chemical stability, particularly at elevated temperatures.

Solders will not directly wet either GaAs or ceramic packaging materials. To achieve soldered joints, the rear surface of the 'die' and the corresponding area of the

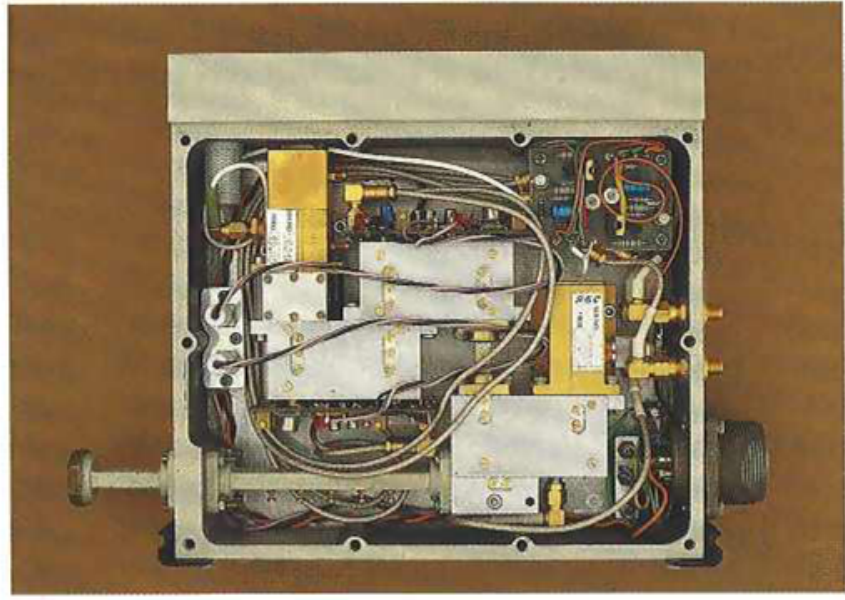

ld

ically 3-8 $\mu \mathrm{m}$ thick, is applied to the top side of the circuits to form conductors and bonding pads. Soft gold bonding pads are compatible with the fine gold wires that are used for making electrical connection to the circuits.

Fig. 1c The GaAs wafer is diced to separate the individual circuits. One of these circuits which is shown is a digital phase shifter measuring only $3.8 \times 2.7 \mathrm{~mm}$ and capable of operating at $100 \mathrm{GHz}$. A gold metallization is applied to the underside of the circuit to provide a solderable surface for attaching the circuit to a substrate.

Fig. 1d The GaAs circuits are soldered to gold metallized ceramic substrates and fine gold wires are used to complete the electrical connections in the functional modules. Extensive use is made of gold for the conduction tracks on the substrates, taking advantage of the high electrical conductivity and tarnish resistance of this metal and its compatibility with the wire interconnects. The underside 
ceramic package must be coated with a metallization that the solder can wet. One of the simplest and most economical methods of metallizing GaAs devices for die bonding that is currently used is to evaporate a layer of gold directly onto the rear surface of the chip. The layer is typically between 0.5 and $1 \mu \mathrm{m}$ thick.

A pure gold layer, however, does not form an ohmic contact to the back of the chip [1], but often this is not a necessary requirement. If a low-resistance contact to the GaAs chip is required, this is generally provided by a coating of a Au-Ge-Ni alloy, often overlaid by a gold plating. The Au-Ge-Ni alloy is deposited onto the rear surface of the GaAs component by evaporation in a vacuum, either sequentially from $\mathrm{Au}-\mathrm{Ge}$ and $\mathrm{Ni}$ sources, or from a single mixed Au-Ge-Ni source. The ohmic contact is formed by heat treating, or 'alloying', the metallization at $375^{\circ} \mathrm{C}$, typically for one minute. The microstructure of the resulting alloyed layer and the relationship between this and the electrical properties of the joint have been investigated and reported in the literature $[2,3]$. Other metallizations are also used to provide ohmic contacts: these have been collated and summarized by D.V. Morgan in Table 3.2 of reference [1]. The receiving surface of the ceramic package is usually metallized with a 'thick film' of a proprietary formulation containing gold.

The commonly preferred solder for the die-attach process is the Au-20wt.\% Sn eutectic alloy that melts at $280^{\circ} \mathrm{C}$. Its relatively high melting point ensures that GaAs devices can be operated 'hot', taking advantage of their superior high-temperature performance, without becoming detached from the package. This solder is commonly employed in power amplifiers which tend to run hot. Although the high gold content makes the solder expensive, it does not represent a major cost element in what is a high-value type of product. Lower melting point tin-, bismuth- and indium-based solders are generally used in cheaper consumer products that incorporate low-power GaAs components such as receiving amplifiers and mixers, where no significant heating occurs during operation. Indeed, for optimum electrical performance of these components, they should be kept as cold as possible.

\section{Quality of Soldered Joints to GaAs}

Soldered joints to GaAs components are generally found to be mechanically weak compared with joints made to metal test-pieces, and tend to be poorly filled by the solder. These features have their origin in the thermal instability of GaAs. GaAs itself begins to decompose above $500^{\circ} \mathrm{C}$ at atmospheric pressure and at a significantly lower temperature in a base pressure of $1 \mathrm{mPa}$, that is typically achieved in an industrial vacuum furnace [4]. Under these conditions, the layer of GaAs close to the free surface is observed to decompose into the constituent elements when the material is heated above about $260^{\circ} \mathrm{C}[5,6]$. If a gold contact is applied to the GaAs component, the dissociated gallium out-diffuses into the gold layer to form gold-gallium phases $[7,8]$. Some of the arsenic dissolves into the molten

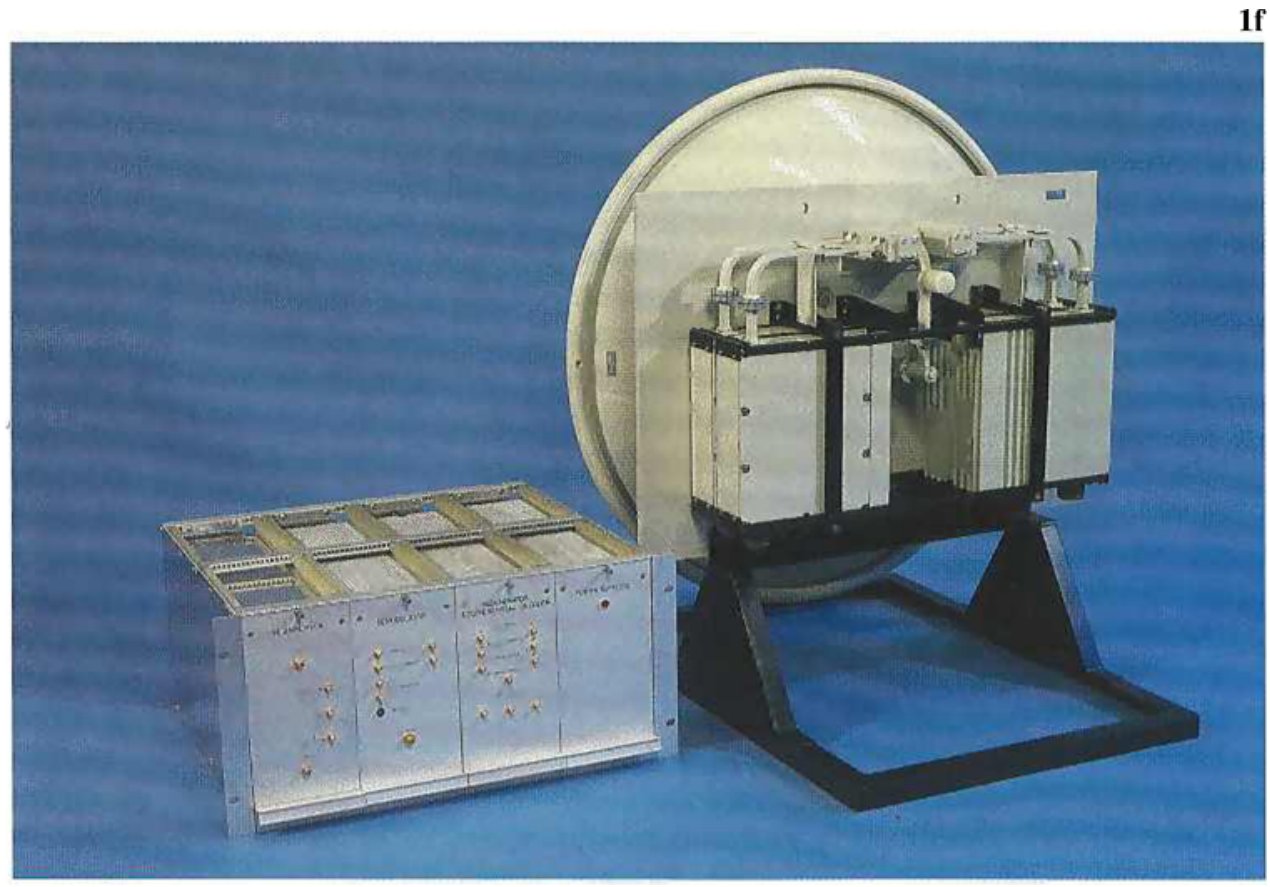

of the ceramic substrate is metallized with gold if it is to be soldered into the package.

Fig. 1e The GaAs modules are combined with conventional silicon devices to produce a communications subsystem. Hard gold platings (typically $\mathrm{Au}=0.1 \% \mathrm{Co}$ ) are applied to the connectors used to interface with the modules. This ensures a reliable, and low resistance electrical path between the various components.

Fig. If A complete microwave transmitter/receiver incorporating the sub-system of GaAs circuits 


\begin{tabular}{|c|c|}
\hline \multicolumn{2}{|c|}{ Tabl } \\
\hline \multicolumn{2}{|c|}{$\begin{array}{l}\text { Eutectic Solder Compositions Studied } \\
\text { and their Melting Points }\end{array}$} \\
\hline Solder composition & Melting point \\
\hline Au-20wt.\%Sn & $280^{\circ} \mathrm{C}$ \\
\hline Sn-3.5wt.\%Ag & $221^{\circ} \mathrm{C}$ \\
\hline Sn-37wt.\%Pb & $183^{\circ} \mathrm{C}$ \\
\hline In- $3 w t . \% A g$ & $143^{\circ} \mathrm{C}$ \\
\hline Bi-43wt.\%Sn & $139^{\circ} \mathrm{C}$ \\
\hline
\end{tabular}

solder on account of the inter-solubility between arsenic, gallium and the constituents of solder alloys. Subsequent reactions occur between these elements to form various intermetallic phases. The arsenic that is not taken up by the solder is lost by volatilization [4,9]. The arsenic outgassing through the joint is responsible for generating large void volumes.

On combining with the gallium-enriched gold metallization, the molten solder, which is a binary alloy in most cases, thus forms an alloy containing up to five components. This in turn can give rise to a complex assemblage of phases on cooling and embrittled joints may result.

\section{Experimental Study}

In the study reported here, the joints formed to GaAs using some of the more widely used metallization/solder combinations were evaluated. The solders investigated were the Au-20wt. $\% \mathrm{Sn}, \mathrm{Sn}-3.5 \mathrm{wt} . \% \mathrm{Ag}, \mathrm{Sn}-37 \mathrm{wt} . \% \mathrm{~Pb}$, In-3wt.\% Ag and Bi-43wt. \%Sn eutectic alloys, the melting points of which are given in Table I. The effect of the bonding temperature on the integrity of the resulting joint was examined. The limiting features are identified and analysed. The sensitivity of the joining process to temperature is a key relationship from an applications point of view because it determines the tolerance of the particular joining operation, which is crucial to its viability as an industrial process.

For one of the solders, the Au-20wt.\%Sn alloy, the 'window' of suitable conditions was found to be too narrow to be capable of being reliably met in an industrial process. This consideration led to a modification to this solder being developed that substantially broadens the tolerance of the process. Particular attention is given to the beneficial role of gold in GaAs die-attach technology as the presence of this element is largely a prerequisite for a successful process. Joints made to GaAs with the Au-20wt.\%Sn solder were studied in greater detail than with the others. There were three reasons for this, namely:

1. The quality of joints produced with this solder is reported to be less satisfactory than with other solders and exhibits a wide variability.

2. This is the commonly preferred solder because of its high melting point.

3. The constitution of the relevant Au-Ga-Sn ternary alloy system is established in contrast with those involving the other soldering alloys.

\section{Experimental Procedures}

\section{Fabrication of the Solders}

The standard commercial practice for the die-attach process is to introduce the solder into the joint in the form of a foil preform that is between approximately 25 and $50 \mu \mathrm{m}$ thick. Ingots of each of the alloys were prepared by melting and mixing $2-5 \mathrm{~g}$ weighed quantities of the relevant constituents in $4 \mathrm{~mm}$ diameter silica crucibles under a shroud of ignited hydrogen. The constituent metals used in preparing the solder alloys were Johnson Matthey Grade 1 purity materials. All the alloy ingots, apart from that of the Au-20wt.\% Sn alloy, were rolled to $50 \mu \mathrm{m}$ foil. While it is possible mechanically to reduce the latter alloy to a foil, this alloy has a low ductility and the maximum permissible reduction per

\begin{tabular}{|c|c|c|c|c|}
\hline \multicolumn{5}{|c|}{$\begin{array}{l}\text { Metallization Systems } \\
\text { Used on GaAs Wafer Samples }\end{array}$} \\
\hline $\begin{array}{l}\text { Metallization } \\
\text { (in wt.\%) }\end{array}$ & $\begin{array}{l}\text { Thickness } \\
\mu \mathrm{m}\end{array}$ & $\begin{array}{l}\text { Deposit. } \\
\text { techn. }\end{array}$ & $\begin{array}{l}\text { Heat } \\
\text { treatmt. }\end{array}$ & $\begin{array}{r}\text { Contact } \\
\text { type }\end{array}$ \\
\hline $\mathrm{Au}$ & 0.5 & $\begin{array}{l}\text { thermal } \\
\text { evaporat. }\end{array}$ & none & diode \\
\hline $\begin{array}{l}\mathrm{Ti} \\
\mathrm{Au}\end{array}$ & $\left.\begin{array}{l}0.1 \\
0.4\end{array}\right) \quad b$ & $\begin{array}{l}\text { electron } \\
\text { peam evapor. }\end{array}$ & none & diode \\
\hline $\mathrm{Au}-12 \mathrm{Ge}-5 \mathrm{Ni}$ & 0.1 & $\begin{array}{l}\text { thermal } \\
\text { evaporat. }\end{array}$ & $\begin{array}{l}375 \% \\
1 \mathrm{~min}\end{array}$ & ohmic \\
\hline $\begin{array}{l}\mathrm{Au}-12 \mathrm{Ge}-5 \mathrm{Ni} \\
\mathrm{Au}\end{array}$ & $\left.\begin{array}{l}0.1 \\
5.0\end{array}\right)$ & plating & none & ohmic \\
\hline
\end{tabular}


step is only about two per cent. After each reduction step, the foil has to be annealed before continuing the process.

To facilitate the production of foil of the Au$20 \mathrm{wt} . \% \mathrm{Sn}$ alloy, the chill-block melt-spinning technique was used. Melt-spinning is a rapid-solidification technique which involves forcing a molten charge through a small hole onto a rapidly spinning, watercooled copper wheel. The high rate of heat extraction obtained by this process causes the metal to solidify almost instantaneously on striking the wheel, resulting in the formation of a thin strip of the alloy with an amorphous or micro-crystalline structure. For details of this technique, see reference [10]. By means of this method, foils of the $\mathrm{Au}-20 \mathrm{wt} . \% \mathrm{Sn}$ alloy, approximately $5 \mathrm{~mm}$ wide by $75 \mu \mathrm{m}$ thick, were produced in a single stage from the molten alloy.

\section{Preparation of Bonded Specimens}

The GaAs samples that were used for the experiments were single-crystal wafer elements oriented with the $<111>$ crystallographic direction perpendicular to the plane of the wafer. These samples were metallized with one of a range of metallizations specified in Table II, which are actually used in industrial production. Both the wafer elements and the solder foils were cleaned in 1,1,1- trichloro-ethane in an ultrasonically agitated bath prior to bonding.

The test specimen comprised a pair of wafer elements, approximately $4 \times 4 \times 0.2 \mathrm{~mm}$, with a solder foil sandwiched between them. This arrangement provided two solder-GaAs interfaces in each specimen which

\section{Table III}

\section{Gold Concentration in Joints Made with Three Tin-Based Solders}

\begin{tabular}{|c|c|c|}
\hline Solder & $\begin{array}{l}\text { Expected gold concen- } \\
\text { tration in the joint } \\
\text { wt. } \%\end{array}$ & $\begin{array}{l}\text { Concentration of gold needed to } \\
\text { form AuSn } 4 \text { as the primary phase } \\
\text { wt.\% }\end{array}$ \\
\hline Bi-43wt.\%Sn & 1.8 & 0.8 \\
\hline Sn-37wt.\%Pb & 3.5 & 5.0 \\
\hline Sn-3.5wt.\%Ag & 4.0 & 10.0 \\
\hline
\end{tabular}

Gold concentration in joints made with three tin-based solders to $0.4 \mu \mathrm{m}$ thick gold metallizations, at a superheat of $50^{\circ} \mathrm{C}$, compared with the concentration required to form $\mathrm{AuSn}_{4}$ as the primary phase could be examined and tested together. The specimen was prepared by making up a sandwich of the components, inserting it into a closed silica glass tube, loaded under a weight of $80 \mathrm{~g}(50 \mathrm{kPa})$, and evacuating the tube to a pressure of $0.1 \mathrm{mPa}$. The tube and test specimen were then heated to a preselected temperature in a furnace, with the temperature monitored continuously during the heating cycle by a thermocouple placed against the surface of the uppermost wafer element. The recorded temperatures are considered to be accurate to within $\pm 5^{\circ} \mathrm{C}$.

Samples with all four metallizations listed in Table II were used in the bonding experiments together with the Au-20wt.\%Sn solder. However, only the gold on titanium $(\mathrm{Au} / \mathrm{Ti})$ metallization was used in conjunction with the lower melting point solders; these are the last four alloy compositions listed in Table II.

No bonding trials were conducted using GaAs metallized with the evaporated gold coating and the lower melting point solders due to the high solubility of gold in these alloys. In the absence of a buffer layer between the gold and the GaAs, the solders would dissolve the gold and then de-wet from the exposed GaAs surface, resulting in the loss of the bond.

The gold on gold-germanium-nickel $(\mathrm{Au} / \mathrm{Au}-\mathrm{Ge}-\mathrm{Ni})$ coating that was provided for the study was similarly not suitable for use with the low melting point solders because the gold coating was excessively thick. If the ratio of gold in the metallization to tin in the solder exceeds a certain ratio, the $\mathrm{AuSn}_{4}$ intermetallic compound will form as the primary phase. It is well-known that this situation causes catastrophic embrittlement in gold-plated joints made with tin-based solders (other than the Au20wt.\% Sn composition) [11]. Table III shows the concentration of gold needed to form $\mathrm{AuSn}_{4}$ as the primary phase in the joint with each of the lowmelting-point solders. This consideration does not apply to the $\mathrm{Au} / \mathrm{Ti}$ metallization because it contained substantially less gold. In this case, for all the tin-containing solders, with the exception of the Bi-43wt.\%Sn alloy, the gold contributed by the coating is insufficient to form the $\mathrm{AuSn}_{4}$ 
compound as the primary phase, as can be seen from Table III. This gives the expected gold contents in the joints made to the $\mathrm{Au} / \mathrm{Ti}$ metallization with $50 \mu \mathrm{m}$ foils of the solders.

While these considerations do not apply to the In$3 \mathrm{wt} . \% \mathrm{Ag}$ solder, the specimens prepared with this solder also only employed the Au/Ti metallization, in order that proper comparisons of the results could be made with those obtained with the other low-melting-point solders.

To represent the heating conditions in a typical industrial vacuum furnace, heating cycle times of up to one hour were used, with the specimens held at the soldering temperature for approximately $45 \mathrm{~min}$. A minimum of a triplicate set of specimens was prepared for each combination of metallization, solder and soldering time and temperature.

\section{Assessment of Bond Quality}

Two types of assessment were used to evaluate the quality of bonds made to metallized GaAs wafer elements by the various solder alloys. These were tensile testing and metallographic inspection.

Specimens were prepared for tensile testing by gluing pull-rods, using high-strength epoxy resin, one to each side of the soldered specimen in an aligned jig. Once the adhesive had fully cured, the specimen was axially loaded in a Universal Testing Machine, at a cross-head speed of $10 \mathrm{~mm} \mathrm{~min}^{-1}$ until failure occurred. The value measured for the failure load was then normalized with respect to the exact cross-sectional area of each specimen. At least two tensile test measurements were made for each set of bonding materials and processing conditions.

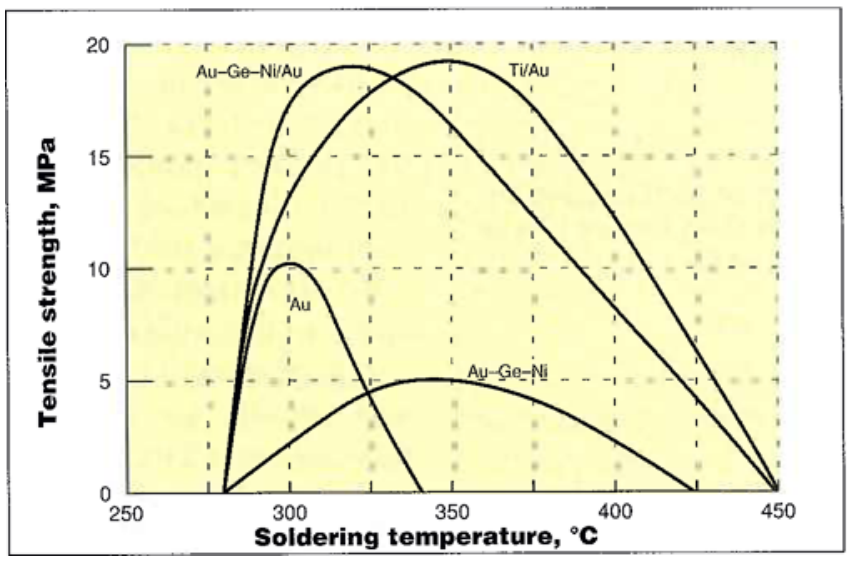

Fig. 3 Tensile strength of soldered joints made between metallized GaAs wafer samples with Au-20wt.\% solder, as a function of the bonding temperature
Specimens for metallographic examination, which generally corresponded to the third in the triplicate set, were cold-mounted in an epoxy resin and subsequently ground and polished by standard methods to reveal a cross-section through the joint.

\section{Results}

\section{The Gold-20wt.\% Tin Solder}

The strengths of soldered joints made between metallized GaAs wafer elements and the Au- 20 wt.\%Sn solder, as a function of the soldering temperature, are shown in Figure 3. The relevant specimens were held at the peak bonding temperature for $45 \mathrm{~min}$.

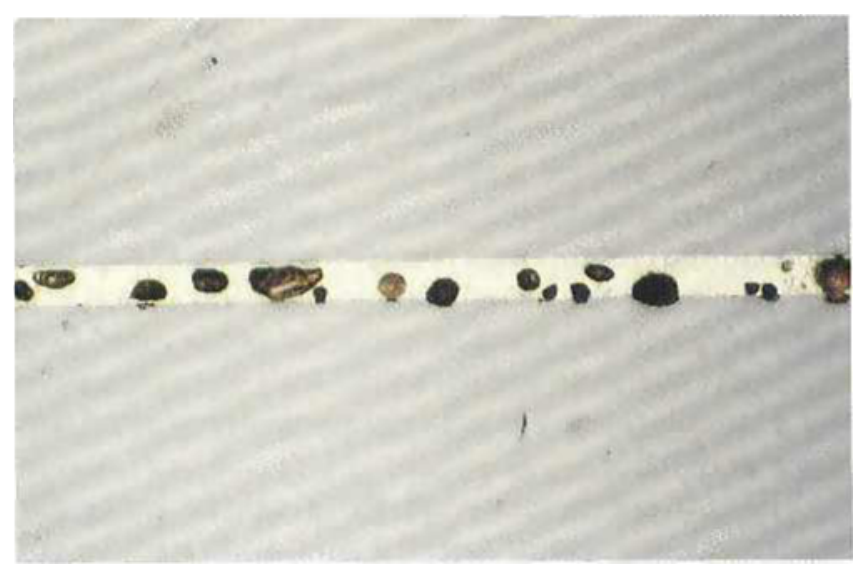

Fig. 2 Joint made between GaAs samples coated with $0.1 \mu \mathrm{m}$ of Ti \& $0.4 \mu \mathrm{m}$ of Au, using the Au-20wt. \% Sn solder at $345^{\circ} \mathrm{C}$. Note the voids in the joint, which are generated by arsenic vapour released from the GaAs. Magnification x 330 .

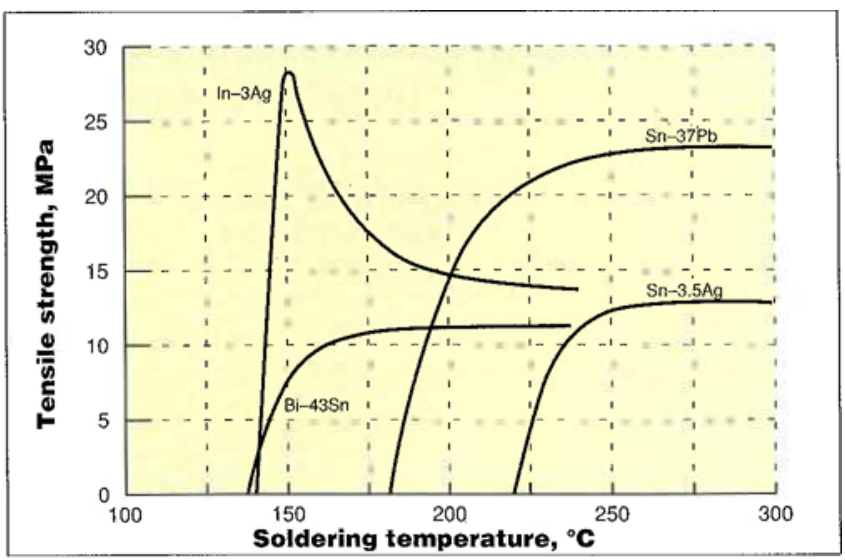

Fig. 4 Tensile strength of soldered joints made between Au/Ti metallized GaAs wafer samples with four lower-melting-point solders, as a function of the bonding temperature 
The strongest and most consistent bonds were formed with the gold on titanium ( $\mathrm{Au} / \mathrm{Ti})$ and the gold on gold-germanium-nickel (Au/Au-Ge-Ni) coatings. For both these metallizations, bond strengths approaching $20 \mathrm{MPa}$ were recorded, as can be seen from Figure 3. The principal features are as follows:

1. At soldering temperatures up to $280^{\circ} \mathrm{C}$, the solder alloy did not show evidence of undergoing a liquid or solid phase reaction with the gold coating on the GaAs wafer elements and zero bond strengths are recorded in Figure 3. The gold coating was intact on these samples.

2. At soldering temperatures between about $290^{\circ} \mathrm{C}$ and $390^{\circ} \mathrm{C}$ the strength of the joints exceeded $10 \mathrm{MPa}$, which is the minimal value for the tensile strength of



Fig. 5 Joint made between GaAs samples coated with $0.1 \mu \mathrm{m}$ of Ti and $0.4 \mu \mathrm{m}$ of Au, using the In-3wt.\% Ag solder. Soldering temperature $200^{\circ} \mathrm{C}$. Au-In intermetallic phases have formed within the body of the solder. The assembly has fractured at one of the interfaces. Magnification x $\mathbf{3 3 0}$.

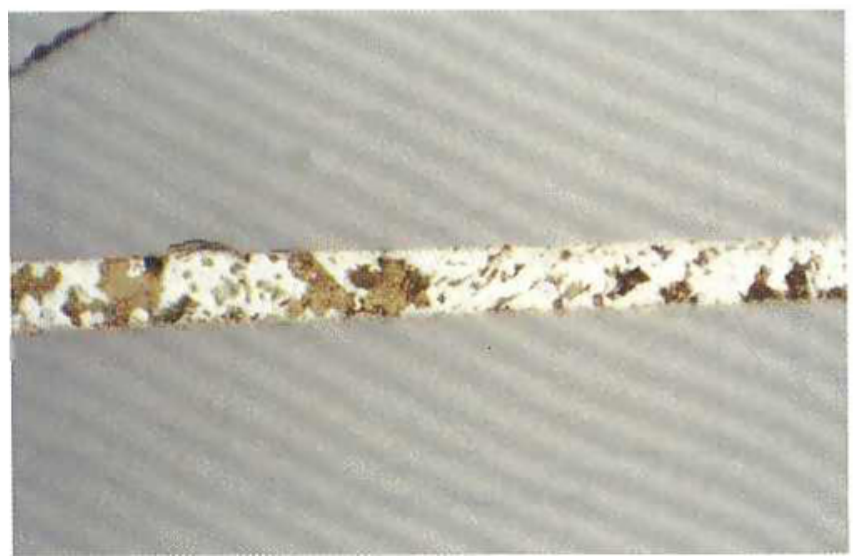

Fig. 7 Joint made between GaAs samples coated with $0.1 \mu \mathrm{m}$ of $\mathrm{Ti}$ and $0.4 \mu \mathrm{m}$ of $\mathrm{Au}$, using the $\mathrm{Sn}-37 \mathrm{wt}$. \% Pb solder at $233^{\circ} \mathrm{C}$. Magnification x 330 . a GaAs single crystal wafer as given in the literature [12], reaching a peak value of $18 \mathrm{MPa}$ at between 320 and $350^{\circ} \mathrm{C}$. Appropriately, specimens soldered over this range of temperatures tended to fail through the GaAs wafer elements in the tensile test, rather than at the interface with the solder. There was no trace of the original gold coating on the surface of the GaAs components.

3. At soldering temperatures above $350^{\circ} \mathrm{C}$, the bond strength decreased with temperature, falling below $10 \mathrm{MPa}$ above about $390^{\circ} \mathrm{C}$. The reduction in strength correlated with an increase in the volume of voids formed at the interface between the solder and the GaAs wafer element, as can be seen from measurements for bonds made to Au/Ti metallized sam-

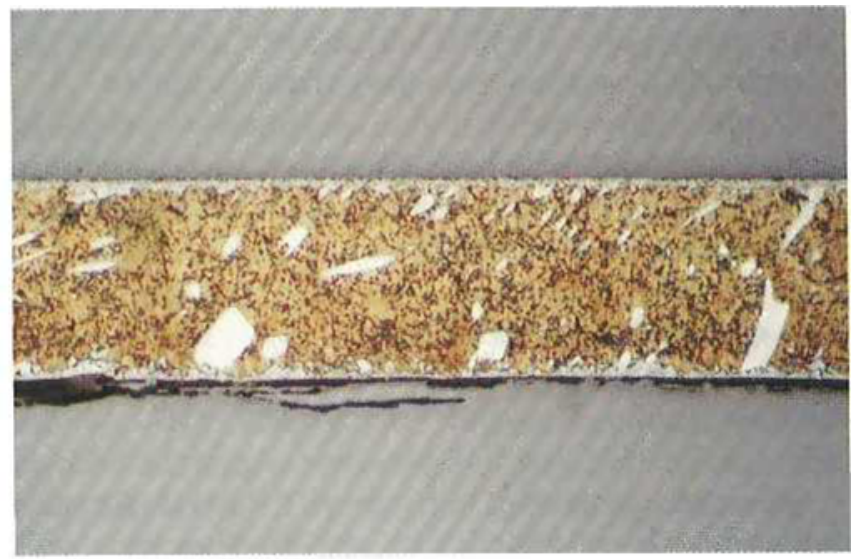

Fig. 6 Same sample as Fig. 5 but with soldering temperature $160^{\circ} \mathrm{C}$. A continuous layer of the intermetallic compound AuIn 2 has formed at the interface between the GaAs samples and the solder. The assembly has fractured at one of the interfaces. Magnification x 330 .



Fig. 8 Joint made between GaAs samples coated with $0.1 \mu \mathrm{m}$ of Ti and $0.4 \mu \mathrm{m}$ of $\mathrm{Au}$, using the $\mathrm{Sn}-3.5 \mathrm{wt}$. $\% \mathrm{Ag}$ solder at $271^{\circ} \mathrm{C}$. The joint contains cracks. Magnification x 330 . 
ples shown in Table IV and is illustrated in Figure 2, which shows a joint soldered at $345^{\circ} \mathrm{C}$ containing voids. With increasing soldering temperature, mechanical failure in the specimens tended to occur at the interface between the wafer elements and the solder, or through the solder itself.

Comparative measurements made on specimens coated with the Au-Ge-Ni metallization, but without the gold overlay, are also shown in Figure 3. The joints formed are consistently much weaker than those where the components had the outer layer of gold.

The bond strengths of specimens which had been coated with an evaporated layer of pure gold $0.5 \mu \mathrm{m}$ thick exhibited a similar behaviour as a function of the soldering temperature, but the peak in the curve was sharper and more attenuated, as shown in Figure 3. For these specimens, the bond strength declined at soldering temperatures above $300^{\circ} \mathrm{C}$ and at $340^{\circ} \mathrm{C}$ the solder had completely de-wetted from the gallium-arsenide.

Varying the time that the specimens coated with evaporated gold were held at the bonding temperature, between 1 and 100 min., made no perceptible difference to the measured bond strength.

\section{Lower Melting Point Solders}

Tensile strength measurements made on series of GaAs specimens, soldered together with the $\mathrm{Sn}$ 3.5wt.\%Ag, Sn-37wt.\%Pb, In-3wt.\% Ag and Bi-43wt.$\%$ Sn solders are shown in Figure 4. All the GaAs specimens had been coated with the titanium plus gold metallization. As with the previous set of specimens, these were held at the peak bonding temperature for $45 \mathrm{~min}$

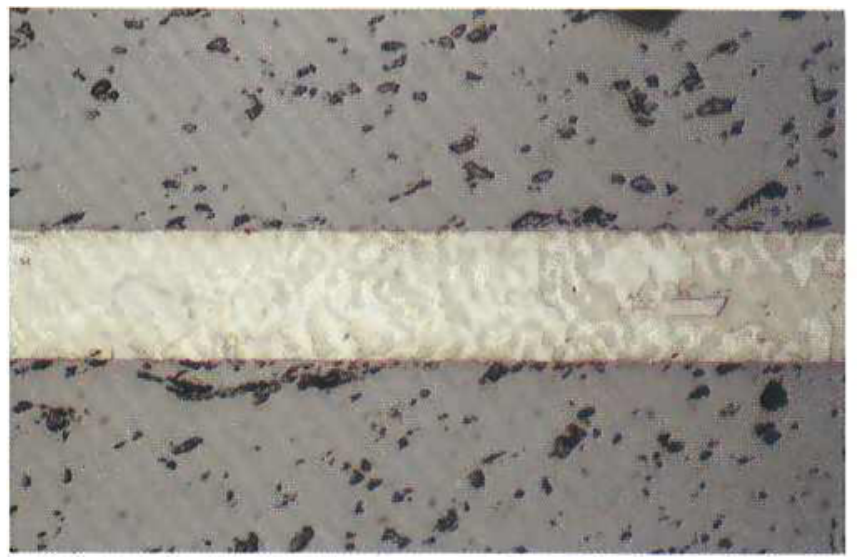

Fig. 9 Joint made between GaAs samples coated with $0.1 \mu \mathrm{m}$ of $\mathrm{Ti}$ and $0.4 \mu \mathrm{m}$ of $\mathrm{Au}$, using the $\mathrm{Bi}-43 w \mathrm{t}$. \% Sn solder at $188^{\circ} \mathrm{C}$. Grains of the AuSn 4 intermetallic compound are embedded in the eutectic solder. Magnification x 330 .

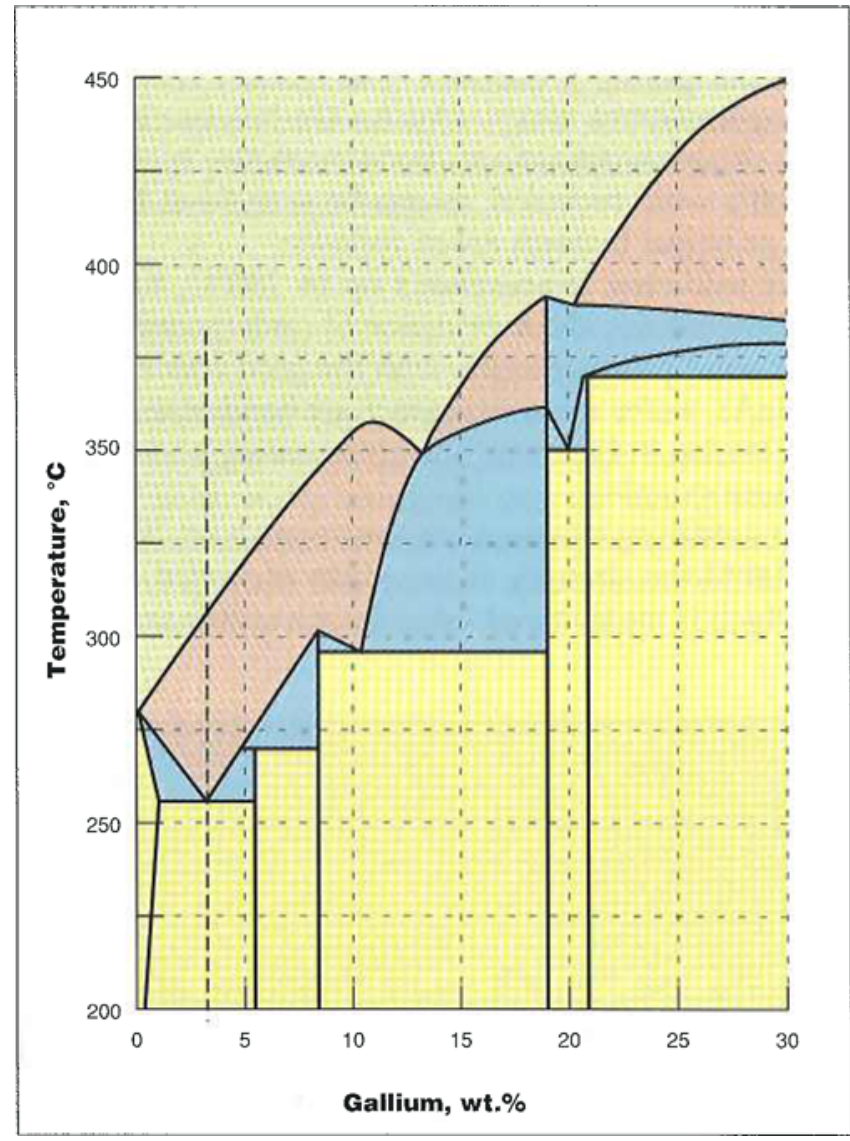

Fig. 10 The section from Au-20wt.\% Sn towards Ga in the Au-Sn-Ga ternary phase diagram. Colour key:

Green $=$ wholly liquid phase;

Red = liquid \& 1 solid phase;

Blue = liquid \& 2 solid phases;

Yellow $=$ wholly solid phase

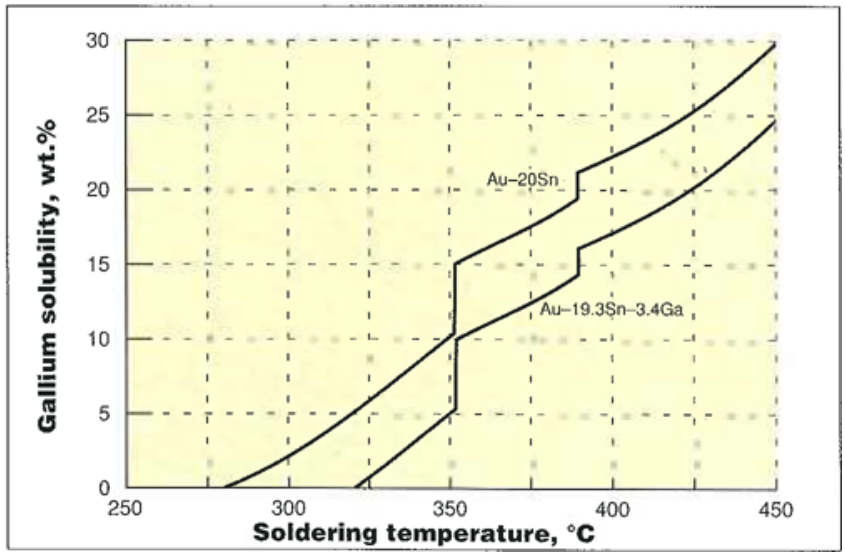

Fig. 11 Solubility of Ga in molten Au-20wt.\% Sn solder with and without a 3.4wt.\% Ga addition, as a function of temperature (derived from alloy constitutional data) 
The variation of bond strength with soldering temperature for these specimens deviated in certain respects from those soldered with the $\mathrm{Au}-20 \mathrm{wt} . \% \mathrm{Sn}$ alloy. The principal features of the bond strengths as a function of temperature, recorded for these soldered assemblies were:

1. For peak soldering temperatures up to essentially the melting point of the particular solder, no reactions were observed within the joint and zero bond strengths are recorded in Figure 4. The gold coating was intact on these samples.

2. For specimens bonded at temperatures between the melting point of the solder and $100^{\circ} \mathrm{C}$ above this temperature, the bond strength achieved and essentially maintained a steady value within the range of $10-25 \mathrm{MPa}$, depending on the solder. The specimens bonded with the In-3wt.\%Ag solder were exceptional in exhibiting a peak strength of $27 \mathrm{MPa}$, when soldered at $150^{\circ} \mathrm{C}$, before declining to an average value of $15 \mathrm{MPa}$ at higher soldering temperatures. The average bond strengths of specimens soldered with the other alloys were: $\mathrm{Sn}-37 \mathrm{wt} . \% \mathrm{~Pb}, 23 \mathrm{MPa}$; $\mathrm{Sn}$ 3.5wt.\%Ag, $12.5 \mathrm{MPa}$; Bi-43wt.\%Sn, $12 \mathrm{MPa}$. Failure of specimens in the tensile test occurred within the joint, generally close to the interface with one of the GaAs wafer elements. This is illustrated in Figures 5 and 6 , where a fracture can be seen along the interface between one of the GaAs samples and the In-3wt.\% Ag solder.

The joints made with the Sn-37wt.\%Pb solder were well filled and exhibited a low level of porosity, as shown in Figure 7. No interfacial phases were observed.



Fig. 12 Tensile strength of soldered joints made between GaAs samples, coated with $0.5 \mu \mathrm{m}$ of evaporated $\mathrm{Au}$, showing the effect of adding 3.4wt. \% Ga to the Au-20wt. \% Sn solder
The joints made with the Sn-3.5wt.\%Ag solder contained cracks as shown in Figure 8, which could be ascribed to grain boundary impurities, probably including gallium dissolved from the substrates. These cracks would account for the lower bond strengths recorded for these specimens. The joints made with the $\mathrm{Bi}-43 \mathrm{wt} . \% \mathrm{Sn}$ and In-3wt.\%Ag solders were well filled and contained a low level of voids and other defects, as shown in Figure 9. Isolated grains of $\mathrm{AuSn}_{4}$ can be seen embedded in the Bi- 43 wt.\%Sn eutectic microstructure of the joint. A characteristic feature of the joints made using the indium containing solders was the presence of the $\mathrm{AuIn}_{2}$ phase. This phase was identified as the $\mathrm{AuIn}_{2}$ compound by energy dispersive $\mathrm{X}$-ray analysis (EDAX). At the soldering temperature of $150^{\circ} \mathrm{C}$, the phase $\mathrm{AuIn}_{2}$ forms as an interfacial layer between the solder and the GaAs surface, as shown in Figure 6.

\section{Discussion}

\section{The Gold-20wt.\% Tin solder}

For GaAs specimens metallized with an outer coating of gold, gallium diffuses into the coating on heating to the soldering temperature, Above $280^{\circ} \mathrm{C}$, the melting point of the Au-20wt.\% alloy, the solder wets the gallium-gold surface layer. As indicated by the slope of the liquidus surface between the solder alloy composition and gallium in the Au-Ga-Sn phase diagram shown in Figure 10, gallium is soluble in the molten solder. Data for the solubility of gallium in the molten solder, as a function of temperature, is given in Figure 11. At small excess temperatures above the melting point of the

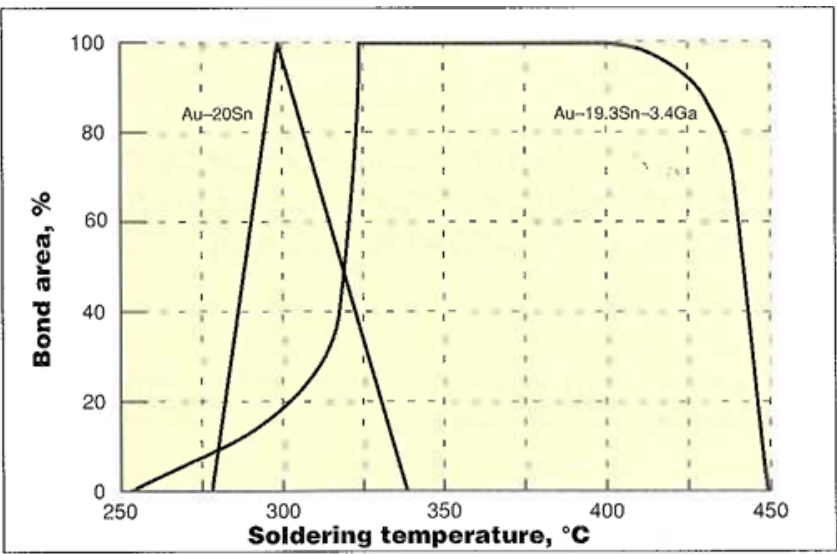

Fig. 13 Relative bond area in soldered joints made between GaAs samples, coated with $0.5 \mu \mathrm{m}$ of evaporated $\mathrm{Au}$, showing the effect of adding 3.4wt.\% Ga to the Au-20wt. \% Sn solder 
solder, the solubility is small: thus, at an excess temperature of $20^{\circ} \mathrm{C}$, the solubility is about $2 \mathrm{wt} . \%$. At such temperatures, some of the gold-gallium layer will remain on the surface of the wafer element, and this ensures a certain bond strength, depending on the metallization.

As the peak bonding temperature is raised, the solubility of gallium in the molten solder increases rapidly. In consequence, the gold-gallium layer progressively dissolves into the solder until it is completely removed. In the case of the evaporated gold layer applied directly to the GaAs wafer element, the solder then proceeds to de-wet from the exposed GaAs surface. Consistent with this explanation is the observation of the rapid increase of voids in the joints of specimens with this metallization that were soldered at temperatures above about $300^{\circ} \mathrm{C}$. However, it is expected that the volatilization of arsenic from the surface of the GaAs components, which increases with the rise in temperature, also contributes to the formation of the voids. As the level of voids increases, not only does the bond weaken but also the thermal and electrical conductances across the joints are reduced correspondingly.

The degradation in the joints occurs much less rapidly with increasing temperature for the wafer elements metallized with $\mathrm{Au} / \mathrm{Au}-\mathrm{Ge}-\mathrm{Ni}$ and $\mathrm{Au} / \mathrm{Ti}$ than for those coated with an evaporated gold layer. The reason for this is made clear by comparing the results for the $\mathrm{Au} / \mathrm{Ti}$ and the evaporated gold specimens. In both cases the gold layer was of approximately the same thickness (0.4 $0.5 \mu \mathrm{m})$. The titanium layer forms a reactive bond to GaAs and also a diffusion barrier between the substrate and the gold. The gold outer layer is dissolved by the

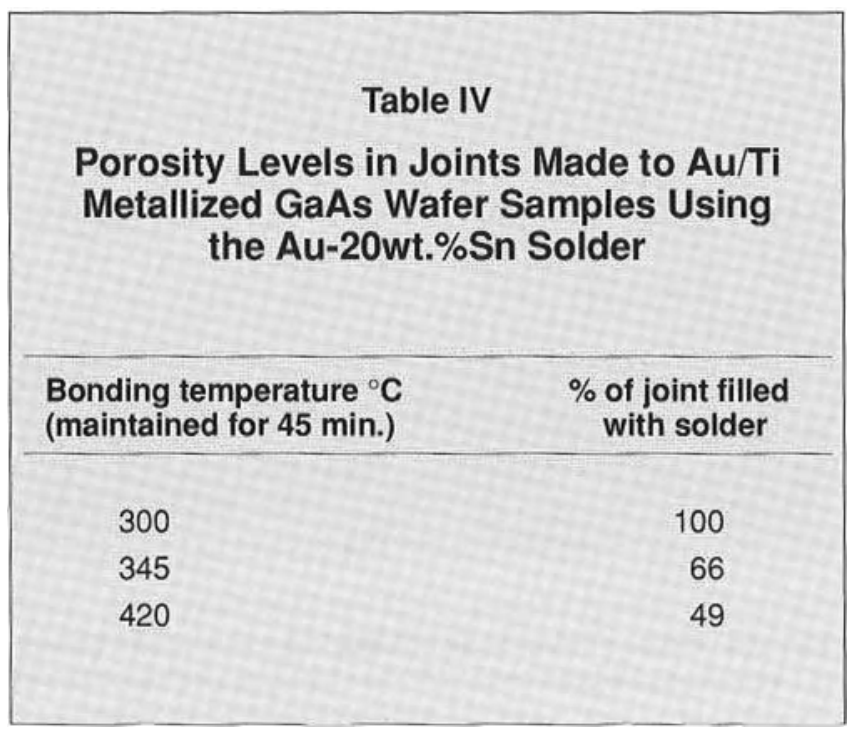

solder, leaving the titanium layer, which is effective in maintaining joint integrity up to temperatures of about $350^{\circ} \mathrm{C}$. The samples coated directly with gold lack this protection, which explains why the respective joints degrade at lower temperatures. At bonding temperatures above $350^{\circ} \mathrm{C}$, the effectiveness of the titanium barrier layer progressively breaks down. This is attested by the erosion of the GaAs surface in contact with the solder that is observed, as well as by the reduced adhesion of the solder and the presence of voids in the joint, at the higher temperatures, which is attributable to arsenic vapour.

It is believed that a protective barrier layer also operates in the case of the $\mathrm{Au} / \mathrm{Au}-\mathrm{Ge}-\mathrm{Ni}$ metallized samples, which accounts for their bond strengths being comparable to those of the Au/Ti metallized samples. The post-deposition heat treatment that is given to the Au-Ge-Ni coating to produce an ohmic contact to the GaAs results in the formation of a continuous $\mathrm{Ni}_{2} \mathrm{GeAs}$ phase close to the interface with the GaAs, while Ni-Ge and $\mathrm{Au}-\mathrm{Ga}$ phases form elsewhere in the metallization layer [3]. On bonding to this layer with the $\mathrm{Au}-$ $20 \mathrm{wt} . \%$ Sn solder, the Au-Ga phases readily dissolve in the solder but the nickel-containing phases act as a barrier between the solder and the GaAs. As the results show, overcoating the Au-Ge-Ni metallization with gold greatly improves the strength of the joints; this suggests that the gold outer layer protects the $\mathrm{Au}-\mathrm{Ge}-\mathrm{Ni}$ metallization from oxidizing and thereby ensures ready wetting by the solder. The weaker joints formed to the unprotected Au-Ge-Ni metallization can be attributed to partial non-wetting and this explanation is consistent with the failure of these bonded specimens at the solder/sub-

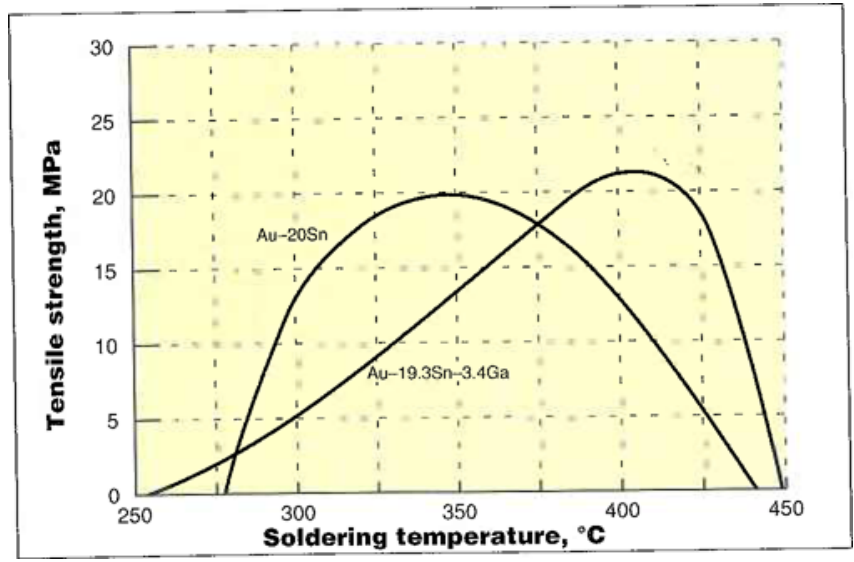

Fig. 14 Tensile strength of joints made to $\mathrm{Au} / \mathrm{Ti}$ metallized GaAs wafer samples, using the unmodified and modified $\mathrm{Au}$ 20wt.\% Sn solders 
strate interface in the tensile test.

The minimum thickness of the gold layer required to protect the underlying $\mathrm{Au} / \mathrm{Au}-\mathrm{Ge}-\mathrm{Ni}$ or $\mathrm{Au} / \mathrm{Ti}$ metallization was not determined in this study. However, the fact that a $0.4 \mu \mathrm{m}$ evaporated layer of gold is sufficiently thick to protect a reactive titanium underlayer and to guarantee the solderability of this metallization over several weeks, suggests that such a layer applied by vapour deposition would also be adequate for the $\mathrm{Au}$ Ge-Ni metallization. However, if electroplating is used, the gold coating needs to be at least $3 \mu \mathrm{m}$ thick to be pore free and afford effective protection to the underlying metallization against oxidation.

\section{Gold-20wt.\% Tin Solder Loaded with Gallium}

Excessive solubility of substrates or components in molten solders is a common problem. One method of lowering the solubility of a given metallization in a solder is to pre-load the solder with the same metal so as to saturate it at the soldering temperature. This approach is used for soldering silver-plated components with tin-lead alloys. Adding $2 \mathrm{wt}$. $\%$ silver to the solder alloy reduces the solubility of silver coatings by almost $70 \%$. This was the original reason behind the development of silver-containing tin-lead solders [13].

It was decided to explore this approach for soldering metallized GaAs components with the Au-20wt.\%Sn solder. A study of the Au-Ga-Sn ternary system indicated that a suitable gallium addition was likely to be

\begin{tabular}{|c|c|c|}
\hline \multicolumn{3}{|c|}{ Table V } \\
\hline \multicolumn{3}{|c|}{ Maximum Tensile Strengths of the Joints } \\
\hline \multicolumn{3}{|c|}{$\begin{array}{l}\text { Made to Au/Ti Metallized GaAs Wafer Samples } \\
\text { and of the Respective Solders in Bulk Form [15] }\end{array}$} \\
\hline \multirow[b]{2}{*}{ Solder } & \multicolumn{2}{|c|}{ Tensile strength (MPa) } \\
\hline & in joint & in bulk form \\
\hline Sn-37wt.\%Pb & 27 & 38 \\
\hline Au-19.3Sn-3.4wt.\%Ga & 22 & - \\
\hline Au-20wt.\%Sn & 20 & 80 \\
\hline In-3wt. \%Ag & 15 & - \\
\hline Sn-3.5wt.\%Ag & 12.5 & 45 \\
\hline $\mathrm{Bi}-43 w t . \% \mathrm{Sn}$ & 12 & 50 \\
\hline \multicolumn{3}{|c|}{$\begin{array}{l}\text { Test speed }=10 \mathrm{~mm} / \mathrm{min} \\
\text { Solder foil thickness }=50 \mu \mathrm{m} \\
(75 \mu \mathrm{m} \text { for Au-20wt. } \% \mathrm{Sn} \text { alloy) }\end{array}$} \\
\hline
\end{tabular}

3.4wt.\%. The Au-19.3wt.\%Sn-3.4wt.\%Ga alloy melts at $255^{\circ} \mathrm{C}$. This composition was chosen because the section through the ternary phase diagram between Au$20 \mathrm{wt} . \% \mathrm{Sn}$ and gallium indicated that solidification of the alloy occurs over a finite temperature interval from liquid to solid with no intermediate phase transformations, as shown by the dotted line in Figure 10. From the alloy constitutional data, it was ascertained that a $3.4 \mathrm{wt}$ \% gallium addition to the solder would reduce the solubility of a gold coating at a given temperature, for example by half at $345^{\circ} \mathrm{C}$, as shown in Figure 11 .

The modified alloy was prepared as a foil by meltspinning and this was used in the preparation of bonded specimens under similar conditions to those employed when using the $\mathrm{Au}-20 \mathrm{wt} . \% \mathrm{Sn}$ solder. The tensile strength of the bonded assemblies metallized with the evaporated gold and incorporating the modified and unmodified solders are shown in Figure 12 for comparison.

The results show the improvement in joint quality obtained with the gallium-loaded Au-Sn solder. The tensile strength is slightly enhanced, and the peak values are shifted towards significantly higher temperatures. The reduced solubility of the metallization in the gallium loaded solder might be expected to extend the mechanical integrity of the bond by $20^{\circ} \mathrm{C}$ at most, according to the solubility data given in Figure 11. In actuality, the joints made with the modified solder retain some strength a full $60^{\circ} \mathrm{C}$ above the temperature at which all strength is lost when the $\mathrm{Au}-20 \mathrm{wt}$.\% Sn solder is used. Clearly, another mechanism must be responsible for the observed changes in the strength of the joints that are produced by the gallium addition to the solder. It is believed that the gallium in the solder mops up arsenic that outgasses from the wafer elements and thereby suppresses the formation of voids. However, above about $350^{\circ} \mathrm{C}$ the volume of arsenic vapour evolved from the substrate can no longer be absorbed by the solder and extensive voids begin to develop in the joint, resulting in loss of integrity. The extent to which the measured tensile strength of the soldered joints correlates with the bond area between the wafer element and the solder can be seen by comparing Figure 12 with Figure 13.

For the Au/Ti metallized specimens, loading the AuSn solder with gallium was found to have a more marked effect in raising the minimum bonding temperature at which strong bonds could be obtained than in extending the range of soldering temperatures that can safely be used. This feature is illustrated in Figure 14, which compares the results for the modified and unmodified solders in conjunction with the $\mathrm{Au} / \mathrm{Ti}$ metallizations. 
The inability of the modified solder to widen the range of bonding temperatures over which strong joints to this metallization are obtained shows that the titanium barrier layer has the effect of 'swamping' much of the benefit of the gallium addition to the solder in aiding joint integrity. The gradual rise in the tensile strength of joints made with the modified solder up to a maximum value is consistent with a steady widening of the solidus-liquidus gap of the solder as gallium and arsenic from the wafer element are progressively dissolved. In consequence, the solder becomes more pasty and fills the joint less effectively. The similarity of the behaviour of the $\mathrm{Au} / \mathrm{Au}-\mathrm{Ge}-\mathrm{Ni}$ metallization to $\mathrm{Au} / \mathrm{Ti}$ with respect to the Au-Sn solder suggests that these conclusions about the effect of the modified solder will apply equally to both metallizations.

\section{Low-Melting-Point Solders}

With all four lower melting point solders, bond strengths higher than $10 \mathrm{MPa}$ were consistently obtained to Au/Ti metallized GaAs samples, as shown in Figure 4. However, the tensile strengths of the joints were below the strengths of the bulk solders, as can be seen from Table V, showing data for the tin-based solders, including $\mathrm{Au}-20 \mathrm{wt} . \% \mathrm{Sn}$. This is consistent with the fact that fracture in the tensile tests occurred either at the interface between the solder and a GaAs wafer element, or within the latter. It is to be noted that the strength of the joint bears no clear relation to the strength, and hardness, of the bulk solder. This is because interfacial effects, including alloying with the gold coating, are the critical factors determining the strength of the joints. That some interaction with the gold coating has occurred is clearly evident from examination of the joint microstructures shown in Figures 5-9. In all cases, the joints contain three phases and sometimes four.

For all the lower-melting-point solders, the joints were made below the $350^{\circ} \mathrm{C}$ threshold at which volatilization of arsenic from the GaAs significantly impairs the integrity of the joint. Consequently, there is no reduction in bond strength, due to the formation of large numbers of voids, at the highest temperatures investigated.

One unusual feature in the bond strength data is the peak in the tensile strength of the bond made with the In $-3 w t . \% \mathrm{Ag}$ solder at $160^{\circ} \mathrm{C}$. This exceptionally high bond strength of $27 \mathrm{MPa}$ appears to be associated with the formation of an adherent $\mathrm{AuIn}_{2}$ intermetallic layer between the GaAs components and the solder, as shown in Figure 6. At higher bonding temperatures, this layer breaks up and disperses, as shown in Figure 5, and the joint strength declines to a steady value.

The relatively inferior strength of the joints made with the Bi-43wt.\%Sn solder is at variance with the comparatively high strength of this solder as compared with the Sn-37wt.\%Pb alloy [14]. This discrepancy might be accounted for by loss of strength of the Bi$43 \mathrm{wt} . \% \mathrm{Sn}$ joints due to the presence in the joint of significant amounts of the embrittling $\mathrm{AuSn}_{4}$ compound as shown in Figure 9 and noted above.

In view of the similar quality of joints made with the lower melting point solders, the choice between them should be made with respect to other criteria, such as melting point, tolerance to the thickness of the gold metallization and overall cost.

\section{Design Guidelines}

This study has furnished a number of design guidelines for die bonding GaAs components:

1. The $\mathrm{Sn}-\mathrm{Ag}, \mathrm{Sn}-\mathrm{Pb}, \mathrm{In}-\mathrm{Ag}, \mathrm{Bi}-\mathrm{Sn}$ and the high melting point Au-Sn eutectic solders are suitable for die bonding GaAs devices in vacuum if they are coated with a metallization that forms a barrier between the GaAs and the solder. Suitable metallizations for the die-attach include the Au-Ge-Ni coating that is commonly used to provide an ohmic contact to GaAs, and titanium, provided that these coatings are protected by a layer of gold.

2. The gold outer metallization is required to protect the contact metallization from oxidation and provide a surface that the solder can wet. This layer should be about $0.4 \mu \mathrm{m}$ thick in order to ensure a solderability 'shelf life' of at least a few weeks. The gold coating must not be much thicker than this if the lower melting point tin-based solders, namely the $\mathrm{Sn}-\mathrm{Ag}$, $\mathrm{Sn}-\mathrm{Pb}$ or $\mathrm{Bi}-\mathrm{Sn}$ alloys, are used in order to prevent the formation of the embrittling $\mathrm{AuSn}_{4}$ intermetallic compound.

3. These lower melting point tin-based solders $(\mathrm{Sn}-\mathrm{Pb}$, $\mathrm{Sn}-\mathrm{Ag}$ and Bi-Sn alloys) cannot be used with GaAs components that are directly coated with gold, because the solders will scavenge the metallization and complete de-wetting will occur. The Au-20wt. $\% \mathrm{Sn}$ solder does not form reliable joints to such components and should not be used in this application.

4. However, as a result of this study, a modified solder has been developed, of composition $\mathrm{Au}-19.3 \mathrm{wt} . \% \mathrm{Sn}$ $3.4 \mathrm{wt} . \% \mathrm{Ga}$ (i.e. Au-20wt.\% solder with a $3.4 \mathrm{wt} \%$ addition of gallium), which enables GaAs components, coated directly with a layer of gold, to be 
reliably bonded over a temperature range comparable to that for the higher quality gold on titanium and gold on gold-germanium-nickel metallizations (340$420^{\circ} \mathrm{C}$ ).

5. In terms of joint integrity in GaAs die bonding, there is little to choose between the lower melting point $\mathrm{Sn}-\mathrm{Ag}, \mathrm{Sn}-\mathrm{Pb}, \mathrm{In}-\mathrm{Ag}$ and Bi-Sn solders. The indiumbased solder has the specific advantage of being tolerant to gold, and should be used if the gold coating on the GaAs component and on the package bondpad are each thicker than about $5 \%$ of the width of the available solder foil. Under these conditions the lower melting point tin-based solders would produce joint embrittlement due to the formation of the $\mathrm{AuSn}_{4}$ intermetallic compound. The $\mathrm{Bi}-\mathrm{Sn}$ solder is the least tolerant in this regard.

6. For all the solders considered, the best results are obtained when the bonding temperature is about $50^{\circ} \mathrm{C}$ above the melting point (liquidus temperature) of the soldering alloy. The soldering temperature should never exceed about $390^{\circ} \mathrm{C}$ because the volatilization of arsenic from the surface of the GaAs will give rise to de-wetting of the solder and prevent joints of satisfactory integrity from being formed.

7. Due to the thermal decomposition of the surface of the GaAs at temperatures above about $350^{\circ} \mathrm{C}$, the Au-20wt.\%Sn alloy is likely to be the highest melting point solder that can be used for the die-attach process with conventional metallizations on the GaAs and vacuum furnacing.

\section{Acknowledgements}

The contributions of Dr K.B. Guy and the late Dr D.S. Evans, both formerly of the GEC Hirst Research Centre, to this study are gratefully acknowledged. The World Gold Council and the General Electric Company are acknowledged for supporting the work.

\section{References}

1 D.V. Morgan, 'Interdiffusion of metal films on gallium arsenide and indium phosphide', in Reliability and degradation: semiconductor devices and circuits,
Ed. M.J. Howes and D.V. Morgan, Chichester, 1981, 151-89

$2 \mathrm{X}$. Zhang and A.E. Staton-Bevan, 'A TEM investigation of NiAuGe ohmic contacts to GaAs', Inst. Phys. Conf. Ser. no. 87, 1987, Section 4, 303-08

3 T.S. Kuan et al., 'Electron microscope studies of an alloyed $\mathrm{Au} / \mathrm{Ni} / \mathrm{Au}-\mathrm{Ge}$ ohmic contact to GaAs', J.Appl. Phys., 1983, 54, 6952-57

4 D.P. Miller, J.G. Harper and T.R. Perry, 'Hightemperature oxidation and vacuum dissociation studies on the $A(111)$ and $B(111)$ surfaces of gallium arsenide', J. Electrochem. Soc., 1961, 108, 1123-26

5 D.C. Miller, "The alloying of gold and gold alloy ohmic contact metallizations with gallium arsenide', J. Electrochem. Soc., 1980, 127, 467-75

6 T. Sebestyen, T. Menyhard and D. Szigethy, 'In situ measurements of arsenic losses during annealing of usual evaporated contacts of GaAs Gunn diodes', Electron. Lett., 1976, 12, 96-97

7 C.J. Madams, D.V. Morgan and M.J. Howes, 'Outmigration of Ga from Au-GaAs interfaces', Electron. Lett., 1975, 11, 574-75

8 P. Ram et al., 'Diffusion of gallium in thin gold films on GaAs', Thin Solid Films, 1987, 150, 58-62

9 T. Sebestyen, I. Mojzes and D. Szigethy, 'Use of Ga in metal-GaAs contacts to eliminate large As loss peaks', Electron. Lett., 1980, 16, 504-05

10 H. Jónes, 'Rapid solidification of metals and alloys', Inst. Metallurgists Monograph No. 8, London, 1982

11 D.M. Jacobson and G. Humpston, 'Gold coatings for fluxless soldering', Gold Bull., 1989, 22(1), 9-18

12 E.A. Fattakhov, T.D. Lisovskaya and A.V. Roshchina, 'Mechanical strength of monocrystalline GaAs', Izv. Akad, Nauk. SSSR, Neorg. Mater., 1980, 16, 1669 71, (in Russian)

13 H.H. Manko, 'Solders and soldering. Materials, design, production and analysis for reliable bonding', 2nd edn., New York, 1979, 122

14 K.S. Dogra, 'A bismuth tin alloy for hermetic seals', Bull. Bismuth Inst., 1987, 52, 8-11

15 'Solder alloy data. Mechanical properties of solders and soldered joints', Int. Tin Research Inst., Publ. No. 656, London, 1986 